\title{
Communication, ideation and contraceptive use in Burkina Faso: an application of the propensity score matching method
}

\author{
Stella Babalola, Claudia Vonrasek
}

\section{Abstract}

Objective The study aim was to assess the effects of a multi-component communication campaign that promoted contraceptive use in Burkina Faso.

Methods This was a cross-sectional survey conducted in 2001 involving 1421 women of reproductive age from Ouagadougou and Bobo-Dioulasso. Participants during the 2001 survey were randomly selected from 54 enumeration areas that were covered during the 1999 Demographic and Health Survey. The propensity score matching (PSM) technique was the analytical method used to assess the effects of the campaign.

Results More than three-quarters of the respondents reported exposure to at least one example of campaign material. Compared with no exposure, high campaign exposure is associated with an adjusted increase of 21.8 percentage points in the proportion of women currently using modern contraceptive methods. Similarly, low exposure is associated with a 7.3 percentage point increase over no exposure. The campaign is also associated with increased knowledge about contraceptives and more favourable attitudes towards family planning.

Conclusions The multiple-component nature of the campaign makes it easy for many members of the target audience to hear consistent messages from a variety of sources. This is a key element responsible for the documented effectiveness of the campaign. Despite its limitations, the PSM technique is a straightforward method that should be used more often to assess the effects of communication programmes.

J Fam Plann Reprod Health Care 2005; 31(3): 207-212 (Accepted 21 January 2005)

Key message points

- Communication programmes are more effective in changing contraceptive behaviours when people are exposed to consistent messages from multiple sources.

- At low levels of exposure, much of the impact of communication is indirect and filtered through the ideational variables influencing contraceptive use.

- Propensity score matching is a useful technique for documenting the effects of communication interventions.

Johns Hopkins University, Bloomberg School of Public Health, Center for Communication Programs, Baltimore, MD, USA

Stella Babalola, PhD, Senior Program Evaluation Officer Claudia Vonrasek, MPH, Senior Program Officer

Correspondence to: Stella Babalola, Johns Hopkins University, Bloomberg School of Public Health, Center for Communication Programs, 111 Market Place, Baltimore, MD 21202, USA

E-mail: SBABALOL@jhuccp.org

\section{Background}

Burkina Faso, a landlocked West African country of about 13.6 million people, is one of the most densely populated nations in the West Africa region. ${ }^{1}$ As in most countries in the region, reproductive health indicators in Burkina Faso paint a rather unpleasant picture. The country is among the worst affected by the human immunodeficiency virus (HIV) infection in West Africa: in 2001, the adult infection rate was $6.5 \% .^{2}$ In general, Burkinabe women start their reproductive life early and continue bearing children until relatively late in life. The results of the 1998-1999 Demographic and Health Survey (BFDHS-II) show that almost one in two women has started childbearing by the age of 18 years. Among adolescents aged 15-19 years, about one-quarter had at least one child or were pregnant with their first child at the time of the survey. The total fertility rate was 4.1 children per woman in urban areas and 7.3 children per woman in rural areas. Moreover, contraceptive prevalence is very low among women of reproductive age in Burkina Faso. In 1999, nationwide, only $5.8 \%$ of women were currently using a method, while in urban areas the contraceptive prevalence was only $20.1 \% .^{3}$

Against this background of poor reproductive health outcomes, the Burkinabe Government worked with a number of national and international organisations to design and implement appropriate reproductive health interventions. One such intervention was the Gold Circle (GO) initiative, implemented under the United States Agency for International Development (USAID)-funded reproductive health project, Santé Familiale et Prévention du SIDA (SFPS), and aimed at increasing contraceptive use while fostering quality services.

\section{The Gold Circle initiative}

The GO initiative has been described elsewhere. ${ }^{4}$ We will only say here that both the design and the implementation of the initiative are based on a mixture of theory and empirical data. Pre-intervention exploratory research in the four intervention countries assessed the community definition and experience of the quality of family planning services and served as a basis for the design of the initiative. The study revealed that the community generally perceived quality in terms of warm and respectful client-provider interactions, competent provider, affordable services, reasonable waiting time, met needs, and method availability.

Based on the results of the formative research, the GO initiative targeted both the demand and the supply sides. On the supply side, the initiative involved a certification process and the use of a quality of care diagnostic tool to determine the current level of quality of services provided in clinics that routinely receive technical and other forms of assistance from the SFPS project. Using the diagnostic tool, programme staff identified a number of sites that met commonly agreed upon quality indicators and ascribed to them the GO status. These sites were further strengthened through staff training and the provision of relevant equipment and supplies to enable them to provide better quality services. In Burkina Faso, 10 clinics were selected 


\section{ARTICLE}

and designated GO sites every year starting from 1998. By 2001, when the evaluation reported in this article took place, 40 clinics had received the GO status. The $40 \mathrm{GO}$ clinics included primary health facilities and tertiary institutions and were spread over 11 districts in the country. However, the majority of them (18) were located in Ouagadougou and Bobo-Dioulasso. The the SFPS project ended in 2003 and funding for the GO initiative was discontinued.

On the demand side, the GO strategy involved the use of mass media and community activities to empower clients and the community to expect and demand certain standards of quality from providers, promote GO sites, and increase contraceptive use.

The initial launching of the GO initiative took place in 1998 in Burkina Faso. Thereafter, the initiative was relaunched every year until the end of the SFPS project. Typically, the GO promotional activities included electronic media materials, printed materials (including a logo featuring a smiling provider inside a gold circle, a Gold Circle advocacy tool, etc.) and community mobilisation activities. The various campaign materials portrayed providers in GO sites as caring, knowledgeable and willing to listen to their clients. Although campaign messages specifically promoted GO sites, they also encouraged people to visit the family planning clinics closest to them.

In addition to the activities that directly promoted the GO initiative, the GO strategy also included the development and distribution of four short radio and television programmes about family planning. These infomercials were 3-4 minutes long and were developed to provide information on methods, debunk myths and rumours about the methods and provide information on management of side effects. Of the four dramatised infomercials, three were method-specific and covered condoms, injectables and the pill, while one was on the range of methods available in GO and other family planning clinics. They were translated into local languages (Moore and Dioula in Burkina Faso) and were available and broadcast on TV and radio during the GO media campaign in 2001. There were 30 airings of the infomercial on national television and a total of 576 radio airings over a 5-month period between February and July 2001. In addition, video and audiocassettes containing the infomercials were distributed to GO sites and community groups for use during community outreach activities.

\section{Theoretical model}

We use an ideation framework to guide the analyses done in this paper. The suggestion that behaviours could be due to ideas or thoughts dates back to the 18th century German philosopher, Hegel, and was later developed by Max Weber and Louis Dumont. For example, Dumont (1909) argued that the desire to improve one's position economically, politically and in the areas of education and culture led to increased individualisation which in turn led to decreased fertility in France in the 1890s. Another French scholar, Landry, saw the decline of fertility as a reflection of prevailing thought patterns and the increasing rationalisation of behaviour. 5

While the notion that ideational and cultural change has an important role to play in demographic transition did not completely disappear from the demographic transition discourse of the mid-20th century, it was considerably overshadowed by the classic demographic transition theory which stressed the role of modernisation and economic development. ${ }^{6-8}$ It was not until the 1980s that the ideation argument started to become prominent again in demographic literature as an alternative explanation or a valid addition to the classic demographic theory for explaining demographic transition. ${ }^{9-16}$

The ideation model attributes part of individual behavioural change to shifts in the "ways of thinking" or value orientations facilitated intergenerationally through the childrearing process and intragenerationally through the mass media and social interaction and influence. ${ }^{17-20}$ The theoretical basis underlying the ideation model used in this paper is that a person's ways of thinking (which can be measured by a set of psychosocial variables) form a part of the proximate determinants of behaviour. Furthermore, the model assumes that the ideational determinants mediate the behavioural impact of sociodemographic and contextual variables, including communication. ${ }^{17,18,21}$

In analysing the effects of the GO campaign, we posit that the campaign has both direct and indirect (through the ideational variables) effects on contraceptive use. We first examine the effects of campaign exposure on pertinent ideational variables. Subsequently, we look at the impact of the campaign on contraceptive use while controlling for the ideational variables. The ideational variables that we examine are borrowed from leading psychosocial theories and include knowledge about contraceptive methods, personal approval, discussion with others, and personal advocacy.

\section{Data}

The data analysed in this article derive from a 2001 household survey. The survey targeted households in 54 randomly selected enumeration areas (EAs) that were covered during the 1998-1999 BFDHS-II in two urban areas: Ouagadougou and Bobo-Dioulasso. When a particular DHS household could not be located, it was replaced with another randomly selected household from the same EA. In the selected households, all women aged between 15 and 49 years were targeted for interview. Overall, 1421 women (1042 in Ouagadougou and 379 in Bobo-Dioulasso) were interviewed using a questionnaire. The Burkinabe Institut National des Statistiques et de la Démographie co-ordinated the implementation of the survey on behalf of SFPS. The Johns Hopkins Bloomberg School of Public Health/Center for Communication Programs was responsible for the overall design of the survey and provided technical assistance at every stage of its implementation.

\section{Methods}

In this article we use a non-parametric propensity score matching (PSM) technique to evaluate the effects of the GO initiative on attitudes towards family planning and contraceptive use. Introduced about two decades ago by Rosenbaum and Rubin, PSM is becoming an increasingly popular tool in impact evaluation. ${ }^{22-29}$ Although PSM has been around for many years and is becoming increasingly popular in impact evaluation, we have found no evidence that it has been used in the past to document the impact of a family planning communication programme. A detailed description of the PSM technique is beyond the scope of this article; however, further information on the technique used is available from the authors

\section{Results}

A description of the predictor variables used in this paper is presented in Table 1. The sociodemographic distribution of the respondents shows that the sample is on average younger than 35 years and predominantly Moslem. Moreover, the majority listens to the radio or watches the television regularly. We also noted that more than one-third 
Table 1 Distribution of the respondents by the sociodemographic variables used to predict propensity score in Burkina Faso, 2001

\begin{tabular}{lc}
\hline Variable & $\%$ \\
\hline Place of residence & \\
$\quad$ Ouagadougou & 73.3 \\
Bobo-Dioulasso & 26.7 \\
Current age (years) & \\
15-24 & 46.4 \\
$25-34$ & 30.5 \\
35-44 & 17.9 \\
44+ & 5.2 \\
Marital status & 37.5 \\
Never married & 56.3 \\
Married & 7.2 \\
Separated/divorced/widowed & 79.4 \\
Listens to the radio regularly at least once a week & 68.8 \\
Watches television regularly at least once a week & 10.2 \\
Reads magazine/newspaper at least once a month & 38.4 \\
Religion & 61.1 \\
$\quad$ Christian & 0.5 \\
Moslem & \\
Other & 39.7 \\
Education & 24.5 \\
$\quad$ None & 35.8 \\
Primary & 1421 \\
Secondary or higher & \\
Observations $(n)$ & \\
\hline
\end{tabular}

Source: SFPS/JHU/CCP GO Evaluation Survey, Burkina Faso, 2001.

Table 2 Summary statistics for contraceptive use and other outcome variables by level of exposure in Burkina Faso, 2001

\begin{tabular}{llll}
\hline Effects & $\begin{array}{l}\text { Zero } \\
(n=303)\end{array}$ & $\begin{array}{l}\text { Low } \\
(n=367)\end{array}$ & $\begin{array}{l}\text { High } \\
(n=751)\end{array}$ \\
\hline $\begin{array}{l}\text { Number of modern } \\
\text { methods known } \\
\text { (range: 0-8) }\end{array}$ & $4.10(2.22)$ & $5.15(1.85)$ & $6.16 \quad(1.58)$ \\
$\begin{array}{l}\text { Proportion reporting } \\
\text { approval of family } \\
\text { planning (range: } 0-1)\end{array}$ & $0.739(0.440)$ & $0.850(0.357)$ & $0.936(0.245)$ \\
$\begin{array}{l}\text { Proportion reporting } \\
\text { personal advocacy in } \\
\text { favour of family } \\
\text { planning (range: } 0-1)\end{array}$ & $0.172(0.377)$ & $0.338(0.473)$ & $0.632(0.482)$ \\
$\begin{array}{l}\text { Proportion reporting } \\
\text { discussion about } \\
\text { family planning } \\
\text { (range: 0-1) }\end{array}$ & $0.204(0.404)$ & $0.368(0.482)$ & $0.596(0.491)$ \\
$\begin{array}{l}\text { Proportion currently } \\
\text { using a modern } \\
\text { method (range: } 0-1)\end{array}$ & $0.092(0.290)$ & $0.196(0.397)$ & $0.353(0.478)$ \\
\hline
\end{tabular}

Source: SFPS/JHU/CCP GO Evaluation Survey, Burkina Faso, 2001. *SDs are given in parentheses. of the respondents were never married and that very few read magazines or newspapers regularly.

\section{Campaign exposure}

Exposure to the mass media campaign was very high. Almost four-fifths $(78.7 \%)$ of the respondents reportedly saw or heard at least one of the campaign materials and could recall the messages of the material. Overall, $8.8 \%$ could recall the GO promotional campaign messages alone, $17.0 \%$ recalled the infomercials alone and more than half $(52.9 \%)$ recalled messages from both components of the campaign. Subsequently, in the analysis of the effects of the campaign, the term 'high exposure' is used to describe respondents who were exposed to both components of the campaign and 'low exposure' those who were exposed to only one component.

The major sources of exposure to the campaign were the television $(50.1 \%)$, radio $(22.4 \%)$, print media $(4.4 \%)$ and health facility $(3.4 \%)$.

\section{Campaign exposure and ideation}

To assess the effects of exposure on ideational variables, we first compared the outcome between the respondents that were exposed (treated) and those that were not exposed (controls) (Table 2). Subsequently, PSM was used to adjust for observed pre-existing sociodemographic characteristics (Table 3).

As shown in Table 2, the data reveal a significant monotonic increase in each ideational variable by campaign exposure. The data further show that the raw differences by exposure level are particularly large for personal advocacy in favour of family planning and discussion about family planning with others.

The PSM-adjusted effects confirm the dose-response relationship in all cases but also indicate that part of the observed differences in the ideational variables is due to pre-existing differences among the campaign exposure categories (Table 3). For example, while the data show a raw significant difference in knowledge of 1.0 method between the respondents with no exposure and their peers with low exposure, the PSM results show that low exposure resulted in a significant increase of 0.8 methods over zero exposure. In other words, about $20 \%$ of the raw effects of low exposure over zero exposure is due to pre-existing differences between the respondents with zero exposure and those with low exposure. Similarly, adjusting for preexisting characteristics through PSM reduces the magnitude of the observed effects of low exposure over zero exposure on family planning approval by about $25 \%$

Table 3 Raw and adjusted effects of campaign exposure on selected ideational variables in Burkina Faso, 2001

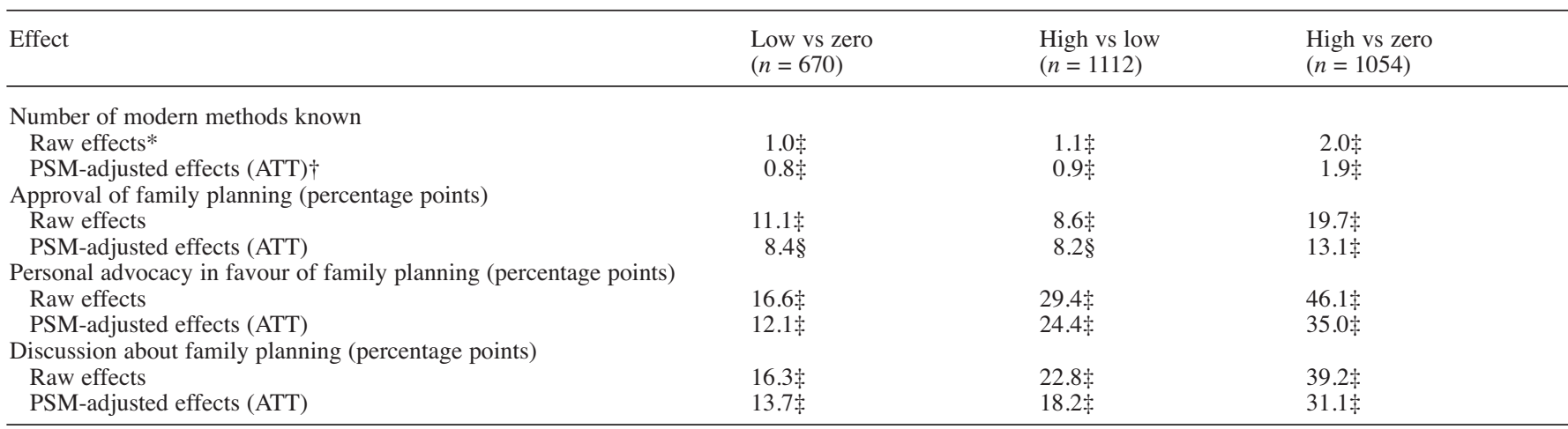

Source: SFPS/JHU/CCP GO Evaluation Survey, Burkina Faso, 2001. *The observed difference in the relevant ideational variable between the respondents in the higher exposure category compared to those in the lower exposure category. It is the absolute difference between the relevant proportions or means. $\dagger$ An indication of how being in the higher exposure category affects ideational variable compared to being in the lower exposure category. It is the difference in the indication of how being in the higher exposure category affects ideational variable compared to being in the lower exposure category. It is the difference in the
mean or the proportion between the higher exposure category and the equivalent lower exposure category. $\ddagger p \leq 0.001$. $\$ p \leq 0.01$. ATT, average treatment effect on the treated; PSM, propensity score matching. 
ARTICLE

Table 4 Estimated effects of campaign exposure on current use of modern contraceptive methods in Burkina Faso, 2001

\begin{tabular}{lcll}
\hline Effect & $\begin{array}{l}\text { Low vs zero } \\
(n=670)\end{array}$ & $\begin{array}{l}\text { High vs low } \\
(n=1112)\end{array}$ & $\begin{array}{l}\text { High vs zero } \\
(n=1054)\end{array}$ \\
\hline $\begin{array}{l}\text { Raw effects* } \\
\begin{array}{l}\text { PSM-adjusted } \\
\text { effects (ATT) } \dagger\end{array}\end{array}$ & $10.4 \ddagger$ & $15.7 \ddagger$ & $26.0 \ddagger$ \\
\hline
\end{tabular}

Source: SFPS/JHU/CCP GO Evaluation Survey, Burkina Faso, 2001 *The observed difference in contraceptive prevalence between the respondents in the higher exposure category compared to those in the lower exposure category. $t$ An indication of how being in the higher exposure category affects contraceptive use cowpared to being in the lower exposure category after adjustment through propensity score. It is the difference in the percent using a modern method between the higher exposure category and the equivalent lower exposure category. $\ddagger p \leq 0.001$. $\$ p \leq 0.05$. ATT, average treatment effect on the treated; PSM, propensity score matching.

and the effects of high exposure relative to zero exposure by about one-third. We noted a similar trend for personal advocacy in favour of family planning and discussion about family planning.

\section{Campaign exposure and contraceptive use}

Overall, about one-quarter $(25.6 \%)$ of the respondents were currently using a modern contraceptive method. Contraceptive prevalence increased monotonically with campaign exposure: $9.3 \%$ of the respondents with zero exposure, $19.6 \%$ of those with low exposure and $35.2 \%$ of those with high exposure reported current use of modern methods. The observed dose-response relationship may reflect the effects of the campaign on contraceptive use but it could also result from self-selectivity bias (the influence of an external factor) or endogeneity (reverse causation). We therefore used PSM to control for confounding pre-existing characteristics. The results are displayed in Table 4

The adjusted effects confirmed that the campaign had a graduated, dose-response effect on contraceptive use: the higher the level of exposure, the greater the gain in contraceptive use. The data showed contraceptive use among the respondents with low campaign exposure would have increased by 13.2 percentage points had they experienced high exposure. Similarly, high exposure increased contraceptive use by more than 21.8 percentage points compared to zero exposure.

The abovementioned PSM results adjust for sociodemographic characteristics, which are not the only factors influencing contraceptive use. Our theoretical framework posits that communication influences contraceptive use directly but also indirectly through its intermediate effects on ideation. There is increasing empirical evidence to show that ideational variables are strong proximate determinants of contraceptive use. $4,17,21$ Failure to take these variables into consideration in the estimation of the effects of the campaign may result in incorrect attribution of effects. We therefore included the propensity score quintile as a covariate in a logistic regression that assesses the impact of campaign exposure on contraceptive use while controlling for ideational variables. The sociodemographic variables used to predict the propensity score were excluded from this latter model. The inclusion of the propensity score in the estimated logistic models helps to account for selectivity on the measured sociodemographic covariates. Moreover, the final model is much simpler than if we had included the eight sociodemographic variables. Using propensity score in regression adjustment is not new and could actually yield more efficient results than matching alone. ${ }^{30-33}$ The approach is, however, not without its shortcomings as we shall discuss later.

Again, three separate models were estimated to account for the multiple-treatment nature of the campaign, and the results are presented in Table 5. In the results presented in this table, the outcome variable is current use of modern methods while the predictor variables are propensity score quintile, campaign exposure and ideational variables.

The analyses show that personal approval of family planning does not have significant independent effects on contraceptive use. In contrast, personal advocacy in favour of family planning, knowledge about contraceptive use and discussion of family planning show the expected positive relationship with contraceptive use. The analyses further reveal that in the presence of ideational variables and the propensity for campaign exposure, low campaign exposure is not associated with a significant increase in contraceptive use compared with zero exposure. In contrast, a high level of exposure makes a significant difference compared with zero exposure or low exposure, controlling for ideational variables. In other words, it appears that what makes a significant difference for increased demand for contraception is considerable exposure to the campaign. At a high level, the campaign has a significant direct impact on contraceptive use, which is not absorbed by the ideational variables. In contrast, at a low level of exposure, much of the impact of the campaign is indirect and filtered through the ideational variables.

Table 5 Results (odds ratio and CIs) of the logistic regression of current use of modern method on campaign exposure, propensity score and selected ideational variables in Burkina Faso, 2001*

\begin{tabular}{|c|c|c|c|}
\hline Sociodemographic predictor & \multicolumn{3}{|c|}{ Odds ratio for contraceptive use } \\
\hline Personal approval of family planning & $\begin{array}{l}2.02 \mathrm{~J} \\
(0.87-4.68)\end{array}$ & $\begin{array}{l}1.69 \mathrm{~J} \\
(0.90-3.19)\end{array}$ & $\begin{array}{l}1.31 \\
(0.66-2.59)\end{array}$ \\
\hline Personal advocacy in favour of family planning & $\begin{array}{l}1.559 \\
(0.93-2.59)\end{array}$ & $\begin{array}{l}2.01 \dagger \\
(1.44-2.81)\end{array}$ & $\begin{array}{l}2.17 \dagger \\
(1.48-3.16)\end{array}$ \\
\hline Number of modern methods known & $\begin{array}{l}1.11 \\
(0.97-1.28)\end{array}$ & $\begin{array}{l}1.15 \$ \\
(1.04-1.26)\end{array}$ & $\begin{array}{l}1.25 \dagger \\
(1.12-1.39)\end{array}$ \\
\hline Propensity score & $\begin{array}{l}1.11 \\
(0.87-4.45)\end{array}$ & $\begin{array}{l}1.01 \\
(0.90-1.12)\end{array}$ & $\begin{array}{l}1.03 \\
(0.92-1.16)\end{array}$ \\
\hline Campaign exposure & $\begin{array}{l}1.58 \mathrm{~J} \\
(0.94-2.65)\end{array}$ & $\begin{array}{l}1.42 \S \\
(1.01-1.98)\end{array}$ & $\begin{array}{l}1.98 \ddagger \\
(1.19-3.29)\end{array}$ \\
\hline Pseudo- $\mathrm{R}^{2}$ (percentage explained) & $9.8 \%$ & $8.6 \%$ & $15.5 \%$ \\
\hline Observations $(n)$ & 670 & 1112 & 1054 \\
\hline
\end{tabular}

Source: SFPS/JHU/CCP GO Evaluation Survey, Burkina Faso, 2001. *95\% CIs are given in parentheses. $\dagger p \leq 0.001 . \ddagger p \leq 0.01$. $\S p \leq 0.05$. Ip $\leq 0.1$. 


\section{Discussion}

This article examines the effects of a communication programme on contraceptive use in urban Burkina Faso. The data showed that the dual-component campaign reached more than three-quarters of the target audience with messages promoting family planning services and modern contraceptive methods. This reinforces the evidence that appropriately designed communication programmes using multiple channels can convey to large audiences consistent messages within a short time.

A dose-response relationship was found between the campaign and selected ideational variables that are likely to influence contraceptive use. The analyses further show that the campaign has a graduated significant impact on contraceptive use. While a low level of exposure to the campaign resulted in some increase in contraceptive use, a high level of exposure had a considerable impact. One recent meta-analysis of the impact of family planning campaigns in developing countries found an average impact (in terms of the difference in contraceptive use between the people exposed to a campaign and those that were not exposed) of 12 percentage points. ${ }^{34}$ In the present study, we found that low exposure was linked to a 13.2 percentage point increase in contraceptive use over zero exposure and high exposure to 21.8 percentage points over zero exposure. The larger than average programme impact associated with the GO campaign testifies to the effectiveness of the strategic communication design used in the programme, although it could also partly be explained by the urban sample on which the analyses are based.

This article joins an increasing body of literature in providing empirical support for the impact of family planning communication campaigns. 4,17,21,34-42 However, this article builds on what we already know. Many of the studies that have examined the impact of family planning campaigns did not use a theoretical model that takes into account the ideational predictors of contraceptive use. The few that based their analyses on an ideational or similar psychosocial model did not examine the dose-response effects of the campaign on both ideational variables and contraceptive use. ${ }^{4,17,21}$

Probably the most significant innovation in this paper concerns the use of the PSM technique. A serious issue in ascribing causal effects using observational data (i.e. data not derived from randomised experiments) is the counterfactual problem. The PSM technique addresses this problem by creating groups of treated and untreated individuals that are statistically equivalent on a set of background characteristics. The method has a considerable advantage over standard statistical methods that control for background variables, such as linear and logistic regression, for two distinct reasons. First, it reduces a set of background variables to a single 'composite' score that appropriately summarises the variables. This reduction in dimensionality makes it easier to see the extent to which treated and untreated groups overlap on background variables. Given such overlap, PSM allows straightforward estimation of treatment effects. Second, unlike regression models, in estimating treatment effects PSM does not rely on any particular functional form for the relationship between the outcome and the predictors within each treatment group.

However, our study has its limitations. First, estimates from PSM rely on the conditional independence assumption, that is, no important variables predicting campaign exposure and contraceptive use are left out of the model used to estimate the propensity scores. It is possible that some important predictors of campaign exposure were unmeasured in our study and therefore excluded from the model. Use of health facilities and life goals (aspirations) are possible examples. Should such variables also predict our outcome variables (contraceptive use and ideation) then our estimates might be biased. 43

The extent to which unobserved variables are a threat to the validity of PSM results can be assessed using sensitivity analysis. ${ }^{44-47}$ In this article we assessed sensitivity to unmeasured variables by estimating the effects of the campaign when specific predictors are excluded from the computation of the propensity score. The strongest predictors of campaign exposure that are also associated with contraceptive use are regular radio listening, regular television viewing, education and current age. When we excluded regular television viewing, the estimated effects of high exposure compared to zero exposure on contraceptive use changed insignificantly by $6.8 \%$. Excluding education changed the effects insignificantly by $5.0 \%$, while excluding regular radio listening changed the estimated effects by $3.2 \%$. We obtained similarly insignificant results when we focused on the effects of high exposure compared to low exposure. In other words, our sensitivity analyses suggest that to bias the measured effect of the campaign, an unmeasured variable would need to have a more powerful effect on campaign exposure than any of the variables that we measured.

Another limitation of our study is that, in order to take the influence of ideation into consideration in our assessment of the effects of the campaign on contraceptive use, we estimated a logistic regression model that controls for propensity score and the ideational variables. There is a problem with using propensity score in this manner. Including propensity score in a regression model reverts to the problem of dimensionality that PSM seeks to avoid. Moreover, Rubin 47,48 has warned that regression adjustment using propensity score can lead to increased bias in the estimates if the treated and the untreated groups are of unequal variance.

\section{Acknowledgements}

Special thanks go Regina Traore, Jane Brown, Youssouf Ouedraogo and Yimian Kabore for their immense contribution to the design, implementation and evaluation of the Gold Circle campaign in Burkina Faso. The authors would also like to acknowledge the staff of the Burkina Faso Institut National des Statistiques et de Demographie (INSD) under the able leadership of François Ilboudo for their role in collecting the data analysed in this paper. Special thanks also go to Brandon Howard for his assistance in editing an earlier version of this paper.

Statements on funding and competing interests

Funding. Funding for this research was provided by the United States Agency for International Development (USAID) under Cooperative Agreement \# 624-00-95-00057-00 to the SFPS Project.

Competing interests. None identified.

References

1 Population Reference Bureau. 2004 World Population Data Sheet. Washington, DC: Population Reference Bureau, 2004.

2 UNAIDS/World Health Organization. Burkina Faso Epidemiological Fact Sheets on HIVIAIDS and Sexually Transmitted Infections - 2002 Update. http://www.who.int/emc-hiv/fact_sheets/ pdfs/Burkina_EN.pdf [Accessed 24 March 2004].

3 Institute National de la Statistique et de la Démographie and Macro International, Inc. Enquête Démographique et de Santé, Burkina Faso 1998-1999. Calverton, MD: Macro International, Inc., 2000.

4 Babalola S, Vondrasek C, Brown J, Traore S. The impact of a regional family planning promotion initiative in West Africa: evidence from Cameroon. Int Fam Plann Perspect 2001; 27: 186-193.

5 Van der Kaa DJ. Anchored narratives: the story and findings of half a century of research into the determinants of fertility. Pop Stud 1996; 50: $389-432$.

6 Kirk D. Population changes and the postwar world. Am Sociol Rev 1944; IX(1-6): 28-35.

7 Davis K. The world demographic transition. Ann Am Acad Pol Soc Sci 1945; 273: 1-11.

8 Notestein FW. Population - the long view. In: Schultz TW (ed.), Food 


\section{ARTICLE/WEBSITE REVIEW}

for the World. Chicago, IL: Chicago University Press, 1945; 37-57.

9 Lesthaeghe R. A Century of Demographic and Cultural Change in Western Europe: An Exploration of Underlying Dimensions. Working Paper No. 1983-1. Brussels, Belgium: Vrije Universiteit Interuniversity Programme in Demography (IDP), 1983.

10 Cleland J. Marital fertility decline in developing countries: theories and evidence. In: Cleland J, Hobcraft J (eds), Reproductive Change in Developing Countries: Insights from the World Fertility Surveys. Developing Countries: Insights from the World Fer

11 Cleland J, Wilson C. Demand theories of the fertility transition: an iconoclastic view. Pop Stud 1987; 41: 5-30.

12 Easterlin RA, Crimmins EN. The Fertility Revolution: A Demand-Supply Analysis, Chicago, IL: University of Chicago Press, 1985

13 Lesthaeghe R. On the social control of human reproduction. Pop Dev Rev 1980; 6: 527-548;

14 Lesthaeghe R. A century of demographic and cultural change in Western Europe: an exploration of underlying dimensions. Pop Dev Rev 1983; 9: 411-435.

15 Lesthaeghe R, Meekers D. Value changes and the dimensions of familism in the European Community. Eur J Pop 1986; 2(3-4): 225-268.

16 Lesthaeghe R, Surkyn J. Cultural dynamics and economic theories of fertility change. Pop Dev Rev 1988; 14: 1-45.

17 Kincaid DL. Social networks, ideation, and contraceptive behavior in Bangladesh: a longitudinal analysis. Soc Sci Med 2000; 50: 215-231.

18 Babalola S, Awasum D, Quenum-Renaud B. The correlates of safe sex practices among Rwandan youth: a positive deviance approach. Afr J AIDS Res 2002; 1: 11-21.

19 Bongaarts J, Watkins SC. Social interactions and contemporary fertility transitions. Pop Dev Rev 1996; 22: 639-682.

20 Mason KO. Explaining fertility transitions. Demography 1997; 34: 443-454.

21 Kincaid DL. Mass media, ideation, and behavior: longitudinal analysis of contraceptive change in the Philippines. Commun Res 2000; 27: 723-763.

22 Rosenbaum P, Rubin D. The central role of the propensity score in observational studies for causal effects. Biometrica 1983; 70: 41-50.

23 Cook EF, Goldman L. Asymmetric stratification: an outline for an efficient method for controlling confounding in cohort studies. Am J Epidemiol 1988; 127: 626-639.

$24 \mathrm{Gu}$ XS, Rosenbaum PR. Comparison of multivariate matching methods: structures, distances, and algorithms. J Comput Graph Stat 1993; 2: 405-520

25 Connors AF, Speroff T, Dawson NV, Thomas C, Harrell FE Jr, Wagner $\mathrm{D}$, et al. The effectiveness of right heart catheterization in the initial care of critically ill patients. SUPPORT Investigators. JAMA 1996; 276: 889-897.

26 Heckman JJ, Ichimura H, Todd PE. Matching as an econometric evaluation estimator: evidence from evaluating a job training programme. Rev Econ Stud 1997; 64: 605-654.

27 Lechner M. Earnings and employment effects of continuous off-thejob training in East Germany after unification. J Bus Econ Stat 1999 17: 74-90.

28 Bryson A, Dorsett R, Purdon S. The Use of Propensity Score Matching in the Evaluation of Active Labour Market Policies. Department for Work and Pensions Working Paper No. 4, 2002. http://www.dwp.gov.uk/asd/asd5/WP4.pdf [Accessed 2 June 2004].

29 Purdon S. Estimating the Impact of Labour Market Programmes. Department for Work and Pensions Working Paper No. 3, 2002.
http://www.dwp.gov.uk/asd/asd5/WP3.pdf [Accessed 2 June 2004].

30 Muller JE, Turi ZG, Stone PH, Rude RE, Raabe DS, Jaffe AS, et al. Digoxin therapy and mortality after myocardial infarction: experience in the MILIS Study. N Engl J Med 1986; 314: 265-271.

31 Berk RA, Newton PJ. Does arrest really deter wife battery? An effort to replicate the findings of the Minneapolis Spouse Abuse Experiment. Am Sociol Rev 1985; 50: 253-262.

32 Berk RA, Newton PJ, Berk SF. What a difference a day makes: an empirical study of the impact of shelters for battered women. $J$ Marriage Fam 1986; 48: 481-490.

33 D'Agastino R. Propensity score methods for bias reduction in the comparison of a treatment to a non-randomised control group. Stat Med 1998; 17: 2265-2281.

34 Snyder LB, Diop-Sidibé N, Badiane L. A meta-analysis of the effectiveness of family planning campaigns in developing countries. Paper presented at the Annual Conference of the International Communication Association, San Diego, CA, USA, May 2003.

35 Westoff C. Rodriguez G. The mass media and family planning in Kenya. Int Fam Plan Perspect 1995; 21: 26-31, 36.

36 Kincaid DL, Merritt PA, Nickerson L, de Castro Buffington S, de Castro MPP, de Castro BM. Impact of mass media vasectom promotion campaign in Brazil. Int Fam Plan Perspect 1996; 22 169-175.

37 Jato MN, Simbakalia C, Tarasevich JM, Awasum DN, Kihinga CNB Ngirwamungul E. The impact of multimedia family planning promotion on the contraceptive behavior of women in Tanzania. Int Fam Plan Perspect 1999; 25: 60-67.

38 Vaughan P, Regis A, St. Catherine E. Effects of an entertainment-education radio soap opera on family planning and HIV prevention in St Lucia. Int Fam Plan Perspect 2000; 26: 148-157.

39 Ronald Freedman. Do family planning programs affect fertility preferences? A literature review. Stud Fam Plann 1997; 28: 1-13.

40 Kane TT, Gueye M, Speizer I, Pacque-Margolis S, Baron D. The impact of a family planning multimedia campaign in Bamako, Mali. Stud Fam Plann 1998; 29: 309-323.

41 Rogers EM, Vaughan PW, Swalehe RM, Rao N, Svenkerud P, Sood $\mathrm{S}$. Effects of an entertainment-education radio soap opera on family planning behavior in Tanzania. Stud Fam Plann 1999; 30: 193-211.

42 Valente TW, Saba WP. Mass media and interpersonal influence in a reproductive health communication campaign in Bolivia. Commun Res 1998; 25: 96-124.

43 Perkins SM, Tu W, Underhill MG, Zhou X, Murray MD. The use of propensity scores in pharmacoepidemiologic research. Pharmacoepidemiol Drug Saf 2000; 9: 93-101.

44 Rosenbaum P, Rubin D. Assessing sensitivity to an unobserved binary covariate in an observational study with binary outcome. J Roy Stat Soc Ser B 1983; 45: 212-218.

45 Lin DY, Psaty BM, Kronmal RA. Assessing the sensitivity of regression results to unmeasured confounders in observational studies. Biometrics 1998; 54: 948-963.

46 Christakis NA, Iwashyna TJ. The health impact of health care on families: a matched cohort study of hospice use by decedents and mortality outcomes in surviving, widowed spouses. Soc Sci Med 2003; 57: 465-475

47 Rubin DB. Matching to remove bias in observational studies. Biometrics 1973; 29: 159-183.

48 Rubin DB. Using multivariate matched sampling and regression adjustment to control bias in observational studies. J Am Stat Assoc 1979; 74: 318-328.

\section{Website Review}

\section{NLH Primary Care Question \\ Answering Service}

"Is doing a pelvic examination with a routine cervical smear any use and do any guidelines exist?"

This thoughtful question was posed on the new pilot site provided by TRIP (Turning Research Into Practice) for the National Library of Health (NLH). The question continued: "In our surgery, some doctors routinely carry out pelvic examination on all women who have thei routine smear test, arguing that this would detect any gynaecological pathology present (e.g. ovarian cancer fibroids). I do not agree with such practice as a 3-yearly pelvic examination on asymptomatic patients does not fulfil the criteria for a screening test, and has a low sensitivity and specificity for detecting cancer".

The reply summarised five references, all of which agreed with the questioner that pelvic examination was a poor tool for detecting ovarian cancer. Among the references quoted was the 6 th edition of Cancer Medicine, which stated that: "The sensitivity and specificity of pelvic examination for the detection of ovarian cancer are imprecisely defined but certainly poor. Many small but potentially life-threatening tumor cannot be felt by palpation nor can the examination differentiate benign from malignan conditions. It is estimated that 10,000 pelvic exaninations are required to t be an early tumor. Generally, detection by bimanual pelvic examination reveals advanced disease".

The other references included the Scottis Intercollegiate Guidelines Network (SIGN) Guideline for ovarian epithelial cancer, which concluded that: "presymptomatic screening by grey scale ultrasound (with or without Doppler) CA125, pelvic examination, or combinations of CA125, pelvic examination, or combinations of
these, are not effective in detecting tumours at an these, are not effective in detecting tumours at an
early stage. No clear evidence was identified as to whether screening in high-risk groups has an impact on mortality from ovarian cancer".
TRIP could find no guidelines that suggested including a pelvic examination at the time of routine cervical smear. Of course, none of the readers of this Journal are doing a pelvic examination as a screening tool in an asymptomatic patient, but they might come across professionals who have not considered the purpose of pelvic examinations and can pass on the website and the references.

If you have a question of general interest to health professionals in primary care you might consider posting it on this site, which is a very useful resource.

Websites: NHL Home: http://www.library. nhs.uk/. Primary Care Question Answering Service provided as a pilot service by TRIP Database: http://www.clinicalanswers.nhs.uk/ index.cfm?question=177.

Reviewed by Gill Wakley, MD, MFFP Visiting Professor in Primary Care Development Staffordshire University and Freelance GP, Writer and Lecturer, Abergavenny, UK 